\title{
Soy-Based Polyols and Polyurethanes
}

\author{
Arnold A. Lubguban ${ }^{1 *}$, Rosal Jane G. Ruda ${ }^{1}$, Rae Homer Aquiatan ${ }^{1}$, Shierlyn Paclijan ${ }^{1}$, \\ Kriztine O. Magadan ${ }^{1}$, Jeffrey Ken B. Balangao ${ }^{1}$, Suzette T. Escalera ${ }^{1}$, Roland R. Bayron ${ }^{1}$, \\ Bobby Debalucos ${ }^{1}$, Alona A. Lubguban ${ }^{1}$, Fu-Hung Hsieh ${ }^{2}$, and Galen J. Suppes ${ }^{2}$ \\ ${ }^{1}$ Center for Sustainable Materials, 306 SET Building, Mindanao State University-Iligan Institute of \\ Technology, Tibanga, Iligan City 9200 \\ ${ }^{2}$ Biomaterials and Bioprocessing Center, W2065 Lafferre \& Nell Hall, University of Missouri, \\ Columbia, MO 65211 USA
}

\begin{abstract}
Polymers derived from plant oils have attracted major commercial interest and significant attention in scientific research because of the availability, biodegradability, and unique properties of triglycerides. Triglycerides rich in unsaturated fatty acids, such as soybean oil (SBO), are particularly susceptible to chemical modification for desired polymeric materials. Soy-based polyols are important industrial prepolymeric materials that use renewable resources; and can be produced or derived through different processing routes. This review paper discusses previous and recent researches about chemical and biochemical polymerization processes to produce soy-based polyols as prepolymers for the production of polyurethane materials in the form of foams (rigid or flexible) and elastomers. The central goal of these research fields is to find effective reaction routes to increase both equivalent weight and hydroxyl functionality of soy-based polyols while taking into consideration the simplicity and economics of these processes.
\end{abstract}

Keywords: polyols; polyurethane; soybean oil; rigid foam

\section{INTRODUCTION}

Polyols are one of the major reactants in polyurethane (PU) formulations. Recent emphasis on renewable content has reactivated interest in natural oil-based polyols to minimize dependency on petrochemical sources and promote green chemistry while taking advantage of the low cost and unique properties of vegetable oils. Various physicochemical and biochemical methods were employed to functionalize the generally less reactive, low molecular weight, and structurally-inconsistent plant oils to produce competitive bio-based polyols (Lubguban et al., 2009).

Some of the early methods of preparing polyols from various vegetable oils suffer from certain drawbacks. Premature degradation occurs by these processes as a result of high temperatures and a relatively long reaction time. Besides, these reactions of preparing polyols from vegetable oils are not very selective. Byproducts in addition to alcohol groups are created during transformation. Greases or waxes often result as a consequence of such chemical transformation. Many available methods of preparing polyols from vegetable oils do not produce products with desirable viscosity and often have strong odour (Bandyopadhyay-Ghosh et al., 2010).

For polyols in PU production, the most important oils are those which contain high concentrations of unsaturated double carbon bonds. In this category of highly unsaturated vegetable oils are: soybean oil, castor oil, sunflower oil, palm oil, rapeseed oil and linseed oil. Soybean oil was chosen over the other oils because it is inexpensive, readily available, renewable 
resource with multiple sites of reactivity including ester and olefinic sites which provides an excellent platform for polymeric materials particularly as a potential alternative to petroleum-based monomers (Luo et al., 2012; Bandyopadhyay-Ghosh et al., 2010).

Soybean oil is a vegetable oil derived from soybean, a species of legume native to East Asia. It is the most produced and most widely used commodity oil in the world (Farhoosh, et al., 2009). The United States alone has the potential to produce about 30 billion pounds of soybean oil and is considered an inexpensive commodity. Refined soybean oil contains more than $99 \%$ triglycerides and typically eight major fatty acids with different degrees of unsaturation, including linoleic, oleic, linolenic, palmitic, and stearic acids. Triacylglycerol molecules in soybean oil vary in fatty acid composition with dominant presence of Linoleic-Linoleic-Linoleic (19\%), Linoleic-Linoleic-Oleic (15\%), LinoleicLinoleic-Linolenic (10\%), Linoleic-Oleic-Palmitic (9\%), Oleic-Linoleic-Oleic (6\%), and OleicLinoleic-Linolenic (6\%). Recently, enhanced breeding technology allows soybeans to produce more reactive fatty acids such as high-oleic content soybean oil. The average number of double bonds per soybean oil molecule is 4.5 (Petrovic, 2008; Debruyne, 2007). The physical and chemical properties of the soybean oil reflect the difference in composition of these fatty acids in terms of chain length, composition, distribution, and location (Wool and Sun, 2005).

Primarily, soybean oil (SBO) is used for food applications, but in recent years research and development efforts have been carried out for utilizing soybean oil in a variety of other applications e.g. thermosetting resins (Wool and Sun, 2005), biodiesel (Teng et al., 2009), polyols for PU applications (Kiatsimkul et al., 2008; Kiatsimkul et al., 2007; Mielewski et al., 2005; Tu et al., 2007), coating materials for Li battery (Kim et al., 2007), bactericidal polyurethane coatings (Bakhshi,et al., 2013), waterborne polyurethane coatings ( $\mathrm{Ni}$,et al., 2010), nanoshells for targeted molecular delivery (Schmidt et al., 2006), and many others. Soybean oil has been an attractive starting raw material for the synthesis of prepolymers or monomers to produce a wide range of different polymers and chemicals. This is owing to its low cost, price stability, and chemical reactivity as a result of its relatively high degree of unsaturation which provides potential reactive sites for polymerization and functionalization (Figure 1). Several review articles devoted to vegetable oilbased polymers and derivatives have recently been published (Petrovic, 2008; Nayak, 2000; Desroches at. al. 2012).

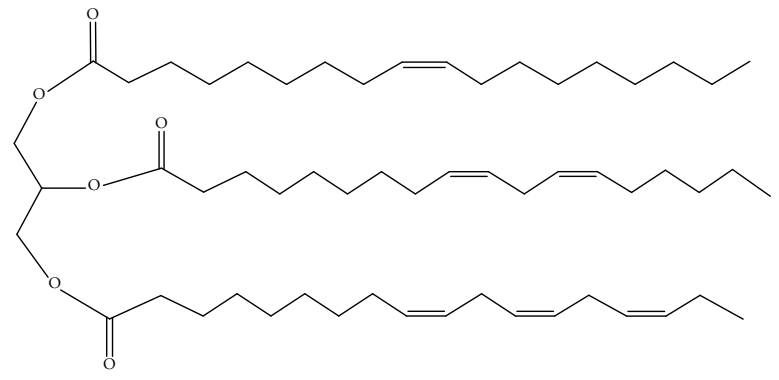

Figure 1. A Structural Representation of Soybean Oil Triacyglycerol.

This review focuses on the versatility of soybean oil as a starting material in the production of polyols for PU foam formulations. A large number of scientific investigations have been conducted on the use of vegetable oil-based polyols and their applications. The main focus of the review is to provide a systematic and concise survey of the recently reported scientific research on the enzymatic and chemical reaction routes involved in soy-based polyol production. This review also includes recent developments in soy-based PU chemistry and technology.

The review is divided into four main parts. The first part (Section 2) describes the importance of increasing the equivalent weight of soybean oil through thermal polymerization with or without the use of catalyst. Higher equivalent weight polyols have significant impact in later PU formulations. A polyol can be initially evaluated for its suitability in PU formulation by using the extractability method as a screening tool.

Biocatalytic modifications of soybean oil through the use of lipases are described in the secondpart (Section 3). Soy-based polyols synthesized from enzymatic biocatalysis is a fairly new technology that has the advantage of high lipase selectivity with the potential for yielding primary hydroxyls which are known to be highly reactive with isocyanate. In addition, enzymatic processes generally use less organic solvents and are performed at lower temperatures.

The third part (Section 4) describes both catalytic and catalyst-free chemical processing of soybean oil to produce polyols. These constitute the most widely researched and used processes in polyol production.

Lastly, the fourth part (Sections 5 and 6) discusses active areas in PU foam technology using these soybased polyols. This section also includes methods to reduce isocyanate consumption in PU formulations and to improve physicochemical properties in $\mathrm{PU}$ foam products. 


\section{THERMAL POLYMERIZATION OF SOYBEAN OIL}

Heat polymerization of soybean oil has the advantage of increasing both the number and weight average molecular weights of the product oil which have significant impact in later PU formulations. Bodying of soybean oil through heating at elevated temperatures involves different reactions which include double-bond migration (producing the more reactive conjugated dienes), other isomerizations, and transesterification (Erhan et al., 2003). These reactions lead to a complex product mixture with an observed increase in viscosity. A soybean oil molecule is composed mainly of glycerides of C-18 fatty acids that contain from none to three non-conjugated double bonds. It is believed that the Diels-Alder condensation step is necessary for crosslinking reactions which requires the participation of conjugated dienes. A slow but progressive migration of the non-conjugated double bonds to the conjugated position can be attained at high temperatures to initiate polymerization (Figure 2) (Powers, 1950; Adams and Powers, 1944).
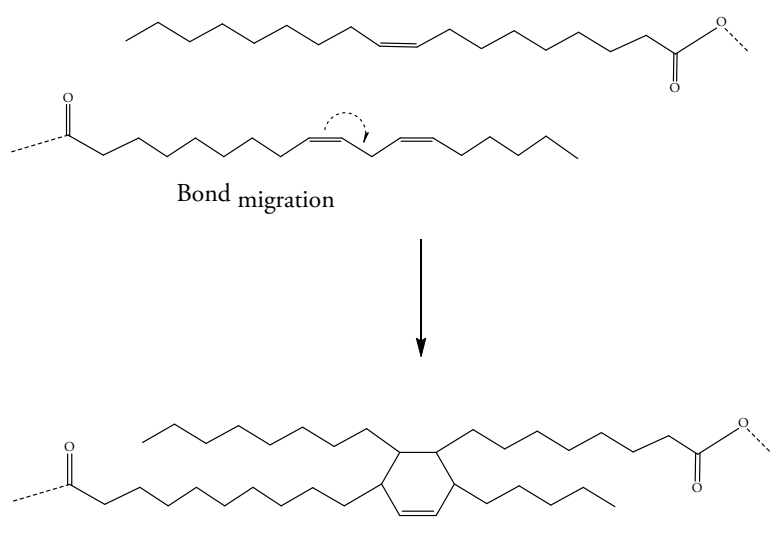

Diels-Alder condensation

Figure 2. Double Bond Shifting to Conjugated Position in Soybean Oil to initiate Diels-Alder Condensation at Bodying Temperatures.

In a kinetic study of heat polymerization of soybean oil in a batch reactor at $330^{\circ} \mathrm{C}$, viscosity increases with time as the iodine number of the oil decreases. The rapid decrease in the degree of unsaturation at the start of the bodying process suggests active participation of linolenic acid which is converted completely forming new fatty acids with similar stereochemistry as linoleic and oleic acids. A simultaneous increase in viscosity is a direct result of oligomerization generally brought about by DielsAlder condensation (Powers, 1950; Lozada et al., 2009). This heat-polymerized soybean oil product is referred to in this article as bodied soybean oil (BSBO). Acid generation in heat polymerization of soybean oil is a function of residence time and temperature. The acid number increases linearly with reaction time and with faster acid generation at higher temperature due to ester bond degradation and formation of volatile fatty acid by-products. Lower temperature bodying promotes low acidity for a given degree of oligomerization (Erhan et al., 2003; Lozada et al., 2009).

Use of Catalysts. Relative to a noncatalyzed reaction, the use of catalysts in heat polymerization of soybean oil leads to decreased reaction times for the same increase in viscosity. The use of catalysts also leads to lower iodine values, and to a decrease in acidity for a given decrease in iodine number (or increase in viscosity) (Lozada et al., 2009; Erhan and Bagby, 1994).

Anthraquinone (9,10-dioxoanthracene) is an aromatic organic catalyst which promotes oligomerization in soybean oil at bodying temperature. It is shown to induce a shift of the nonconjugated double bonds to a conjugated position during thermal treatment of the oil. During this isomerization step, the amount of conjugation reaches a maximum, and then drops off due to polymerization by Diels-Alder reaction (Falkenburg et al., 1948). Adding $2.5-5.0 \%$ by weight of this catalyst shortens polymerization temperature requirement by $30{ }^{\circ} \mathrm{C}$ and heating time by about $50 \%$. Catalysis by anthraquinone also produces less acidity at the same degrees of polymerization (Lozada et al., 2009; Erhan and Bagby, 1994).

Another catalytic method that induces isomerization in soybean oil makes use of metal catalysts such as $\left[\mathrm{RhCl}\left(\mathrm{C}_{8} \mathrm{H}_{14}\right)_{2}\right]_{2}, \mathrm{PtCl}_{2}\left(\mathrm{PPh}_{3}\right)_{2}$, and $\mathrm{RuHCl}(\mathrm{CO})$ $\left(\mathrm{PPh}_{3}\right)_{3}$, where $\mathrm{Ph}$ is a phenyl group. In some instances small amounts of additives are added such as $\left(p-\mathrm{CH}_{3} \mathrm{C}_{6} \mathrm{H}_{4}\right)_{3} \mathrm{P}$ and $\mathrm{SnCl}_{2} \cdot 2 \mathrm{H}_{2} \mathrm{O}$. These catalysts in quantities of $0.1-0.5 \mathrm{~mol} \%$ produce high yields ( $>95 \%$, using $\mathrm{EtOH}$ as solvent) of conjugated soybean oil from regular soybean oil under mild conditions $\left(<100{ }^{\circ} \mathrm{C}\right)$ (Andjelkovic et al., 2005; Larock et al., 2001). Solvent-free isomerization is also possible but requires higher temperature of 212$216^{\circ} \mathrm{C}$ using $\mathrm{RuHCl}(\mathrm{CO})\left(\mathrm{PPh}_{3}\right)_{3}$ as catalyst to yield about 54\% conjugation (Krompiec et al., 1998).

While most of the oligomerization reactions of soybean oil involve a conjugation step to initiate the Diels-Alder reaction which eventually decreases the iodine number, metathesis reactions produce high-molecular weight soybean oil oligomers that preserve the double bonds. Metathesis catalysts are widely used to improve the drying properties of vegetable oils. Several metal catalysts like $\mathrm{Me}_{4} \mathrm{Sn}$ and $\mathrm{WCl}_{6}$ that were used in the past were oxygen- and moisture-sensitive and posed disposal problems. 
Catalysts developed recently such as Grubb's ruthenium carbene catalysts have been shown to promote acyclic diene metathesis to yield high molecular weight soybean oil oligomers under solvent-free conditions at moderate temperatures and low pressures, andshorter reaction times. Other catalyst systems that have shown highly successful performance in acyclic diene metathesis include Schrock's well-defined tungsten and molybdenum alkylidenes (Refvik et al., 1999; Erhan et al., 1997; Tian and Larock, 2002).

Polyol Screening Test: Isocyanate Reactivity. The end-use of the soy-based polyols described in this review will be as B-side components in PU formulations. The authors developed a polyol screening test based on the polyol's reactivity with polymeric diphenylmethane diisocyanate (pMDI) (Lubguban et al., 2009). The method follows the simple urethane bond formation and crosslinking from the basic reaction of the alcohol and -NCO group of the isocyanate (Figure 3). Other reactions are possible when extended to polyfunctional B-side reactants that contain other isocyanate-reactive groups. The A-side (isocyanate) and B-side (polyol) mixture is allowed to cure at $>100^{\circ} \mathrm{C}$ for a period of time after which the PU wafers undergo organic solvent extraction of the unreacted oil.

\begin{tabular}{|c|c|c|}
\hline $\mathrm{R}-\mathrm{N}=\mathrm{C}=\mathrm{O}$ & $\mathrm{R}^{\prime}-\mathrm{H}_{2}-\mathrm{OH}$ & $\stackrel{\Delta}{\longrightarrow} \quad \stackrel{\mathrm{H}}{\stackrel{\mathrm{O}}{\mathrm{II}}{ }_{-}}{ }_{-} \mathrm{O}_{-} \mathrm{C}_{2}-\mathrm{R}^{\prime}$ \\
\hline $\begin{array}{c}\text { A-side } \\
\text { (Isocyanate) }\end{array}$ & $\begin{array}{l}\text { B-side } \\
\text { (Alcohol) }\end{array}$ & Urethane \\
\hline
\end{tabular}

Figure 3. PU Polymer-forming Reaction between an Isocyanate and an Alcohol.

Extractability characterization is used to evaluate isocyanate reactivity with the alcohol groups. A single-step extraction determines the percentage of the unreacted oil phase in the polymer. Low extractability is believed to correlate with high crosslinking, whereas high extractability is believed to correlate with the presence of nonfunctional or single-functional components in the B-side of the urethane formulation (Lubguban et al., 2009). Heatpolymerized soybean oil has shown considerable reactivity and crosslinking with pMDI, especially in comparison with soybean oil, which does not set upon curing. The former has a higher molecular weight and so fewer reactive moieties go farther in reducing extractability. At least some of the functionality in the bodied soybean oil is attributable to cleaved ester bonds, which result in alcohol and acid groups, both of which will react with pMDI (Lubguban et al., 2009). Different degrees of bodying also impact the extractability. Higher degrees of polymerization as reflected in the oil's viscosity result in relatively lower unreacted oil phase extractability of the test wafers
(Figure 4) (Lubguban et al., 2009).

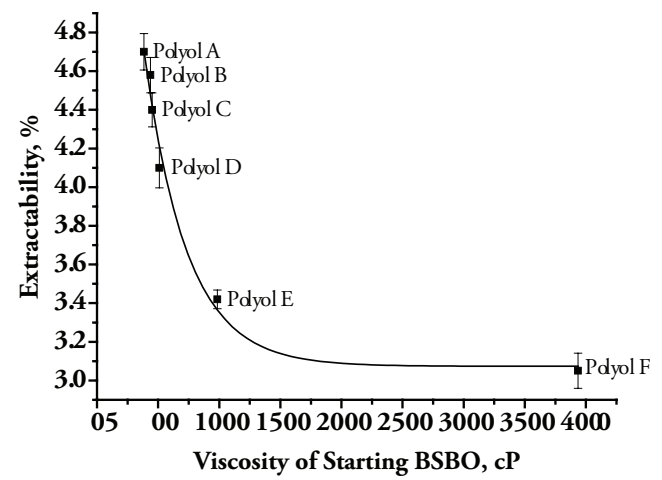

Figure 4. Effect of Viscosity (Degree of Polymerization) of the Starting Bodied Soybean Oil on the Extractability of the Final Soy-based Polyols. All reaction conditions are constant for all samples.

\section{ENZYMATIC ROUTES}

The use of lipases to modify triglyceride chemistry has received increased attention recently with the aim of producing specific end products at highest yield and purity owing to the high specificity, high selectivity, and low energy process requirements of these enzymes. Most of these enzymatic reactions are bench-scale or laboratory set-ups and very few are run as full-scale commercial processes because of the high cost and relatively low operational productivity of most lipases. With advancing enzyme science and technology, the cost of enzymes is likely to go down and such a development is expected provide more opportunities in biocatalytic processes. (Kiatsimkul et al., 2006; Bornscheuer, 2000).

Epoxidation. Several lipases have been shown to catalyze epoxidation reaction in which an oxygen atom is joined to an olefinically unsaturated molecule to form cyclic three-membered ether. Novo Nordisk is credited with the first published report on lipase-catalyzed conversion of fatty acids to peroxy fatty acids with hydrogen peroxide. Mucor miehei, Humicola sp., Pseudomonas sp., and Candida antarctica lipases were shown to convert octanoic acid and hydrogen peroxide $(60 \%)$ into peroxyoctanoic acid of which Novozyme 435 , the immobilized form of C. antarctica on polyacrylate resin, yields the highest (Bjorkling et al., 1990; Knothe and Derksen, 1999).

Chemoenzymatic epoxidation of vegetable oils including soybean oil (Figure 5) offers important advantages over the chemical methods due to the following: mild reaction conditions and neutral $\mathrm{pH}$ of the reaction media; formation of stable hydroxyperoxides directly from fatty acids; high regio- 
and stereoselectivity; and significant suppression of side reactions and high conversion (Vlcek and Petrovic, 2006). In an optimized reaction condition, the conversion of double bonds to epoxy groups can exceed $90 \%$ when the reaction is run at $50{ }^{\circ} \mathrm{C}$ in the presence of at least $4.0 \%$ lipase Candida antarctica (Novozyme 435) immobilized on polymethacrylate resin beads. In addition, the reaction mixture has molar ratios of hydrogen peroxide/double bonds greater than 1 with up to $25 \mathrm{~mol} \%$ free fatty acids (FFA) and $110 \%$ toluene. The reaction of hydrogen peroxide with oleic acid catalyzed with lipase gives oleic peracid which oxidizes double bonds in soybean oil and the FFA itself (oleic acid) to epoxy groups (Vlcek and Petrovic, 2006).

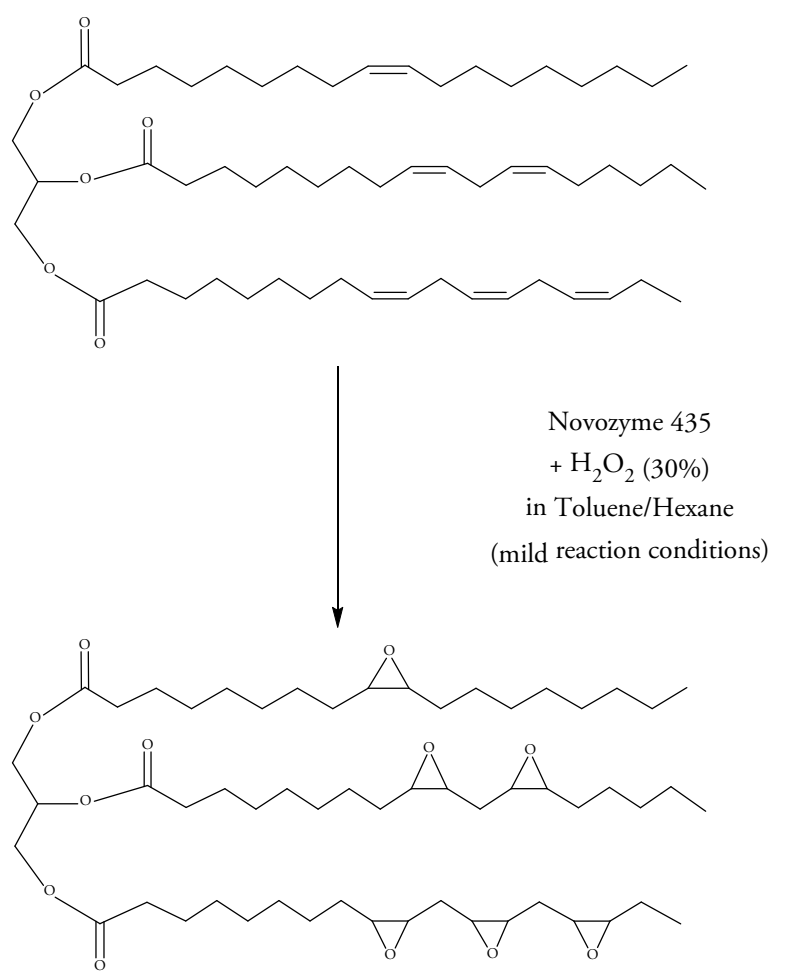

Figure 5. Chemoenzymatic Epoxidation of Soybean Oil.

Free fatty acids (FFA) are important reactants in chemoenzymatic epoxidation of soybean oil and can be synthesized by converting the oil into its FFA components using a $1 \mathrm{~N}$ solution of $\mathrm{KOH}$ in ethanol:water (9:1 v:v) in $48 \mathrm{~h}$ at room temperature (Klaas and Warwel, 1996). Chemoenzymatic "self"-epoxidation of soybean oil is possible by reaction with hydrogen peroxide in the presence of Novozyme ${ }^{\circledast 35}$. The reaction produces epoxidized triglycerides, small quantities of epoxidized free fatty acids, and a significant amount of epoxidized monoand diglycerides which are difficult to separate from the reaction mixture. The addition of excess free fatty acids prevents the undesirable formation of monoand diglycerides formation by reesterifying all the hydroxyl groups. The resulting product will only consist of epoxidized triglycerides and epoxidized free fatty acids which can be easily removed by alkaline washing (Klaas and Warwel, 1996).

Epoxidized soybean oil (ESBO) is derived from the epoxidation of the carbon-carbon double bonds in soybean oil via chemical or chemoenzymatic processes (Kiatsimkul et al., 2006). The resulting oxirane functionality makes $\mathrm{ESBO}$ a reactive derivative for further functionalization to produce highly reactive polyols. ESBO is used as plasticizers, crosslinking agents, pre-polymers, and intermediates for polyol production used in polyurethane, polyester and plastic resins (Kiatsimkul et al., 2006). This can be achieved through oxirane ring opening by hydroxylation or alcoholysis which attaches hydroxyl functionalities to ESBO. The opening or cleavage of the oxirane group opens a myriad of different end-products or intermediates such as ester alcohols, diols, ether alcohols, amino alcohols, and many others (Knothe and Derksen, 1999).

Glycerolysis. Monoglycerides (MG) and diglycerides (DG) are important products in the reaction of soybean oil triglyceride and glycerol (Lubguban et al., 2009). These products are widely used as emulsifiers in foods, cosmetics, and pharmaceutical mixtures (Fregolente et al., 2008). A non-enzymatic reaction of BSBO and glycerol at temperatures greater than $200{ }^{\circ} \mathrm{C}$ produces a high hydroxyl equivalent weight polyol due to the addition of hydroxyl groups in the polymerized soybean oil molecule (Lubguban et al., 2009). The use of lipases to catalyze the glycerolysis of soybean oil was reported with higher yields of both MG and DG (Fregolente et al., 2008; Jackson and King, 1997; Lo et al., 2004; McNeill et al., 1991; Noureddini and Harmeier, 1998). These enzymes include lipases from Pseudomonas sp., Pseudomonas fluorescens, Aspergillus niger, Mucor javanicus, Rhizopus oryzae, Rhizopus niveus, Alcaligenes sp., Candida antarctica, Thermomyces lanuginosus, Candida rugosa, and Rhizomucor miehei. An enzymatic route to the production of hydroxyl-rich poyol from the reaction of $\mathrm{BSBO}$ and glycerol catalyzed by different lipases has not been investigated more thoroughly. Enzymatic glycerolysis has the advantage of using lower temperatures, which prevents the discoloration and alteration of unsaturated fatty acids that is common at elevated temperatures (Jackson and King, 1997).

Hydrolysis. The production of lipases and its application in hydrolysis of triglycerides have been practiced commercially to produce fatty acids ( $\mathrm{Fu}$ et al., 1995). Enzyme hydrolysis has been investigated significantly in the past few years to synthesize soybased polyols (Kiatsimkul et al., 2007). Several 
lipases tested and used for triglyceride hydrolysis in research and industry include Candida cylindracea, Candida rugosa, Burkholderia cepacia, Aspergillus niger, Mucor javanicus, Rhizomucor miehei, Rhizopus delemar, Penicillium sp., Rhizopus niveus, and pancreatic-based (Kiatsimkul et al., 2007; Fu et al., 1995; Park et al., 1988; Yoshida and Alexander, 1983).

Soy-based polyols can be prepared through enzyme catalysis by initially removing fatty acids in the soybean triglyceride structure followed by enzyme hydrolysis to impart the hydroxyl functional groups (Kiatsimkul et al., 2007). Removal of fatty acids can be done randomly or selectively by specific lipases. In a certain study, soybean oil undergoes a heat bodying step to create soy-based oligomers as starting materials that can be subsequently lipasefunctionalized to produce polyols (Figure 6).
The mechanism of heat polymerization of soybean oil is explained in the earlier section (Figure 2). A bodied soybean oil macromolecule is mostly crosslinked at the 2-position of the fatty acid moieties where the 1,3-regiospecific lipases, or most of the lipases have poor reactivity. This leads to the production of bodied soybean oil with multiple primary hydroxyl moieties attached. The significance of initially polymerizing soybean oil triglycerides before $-\mathrm{OH}$ functionalization is that the soy-based polyol will tend to engage more of its mass in the final polyurethane formulation (Kiatsimkul et al., 2007). Candida rugosa lipase has shown to largely hydrolyze palmitic acid, the shortest fatty acid in the soybean oil structure. It is proposed simple and straight configuration of palmitic acid has special affinity to the tunnel-like binding site of the lipas. (Kiatsimkul et al., 2007; Krishna and Karanth, 2002).

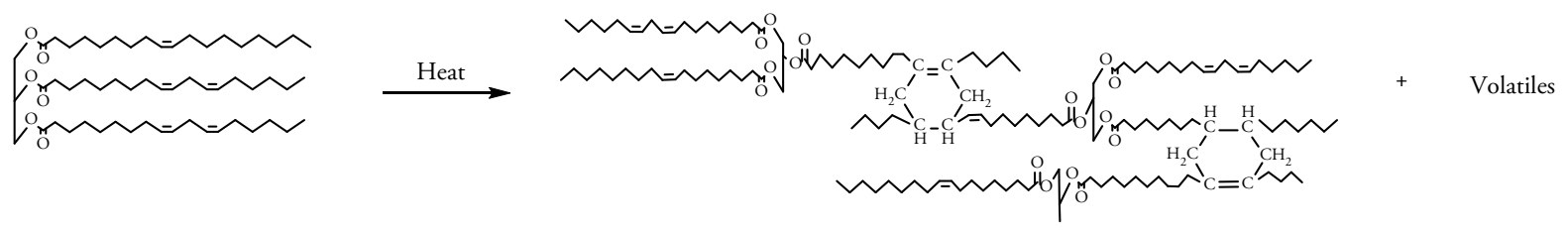

Soybean Oil

Bodied SBO

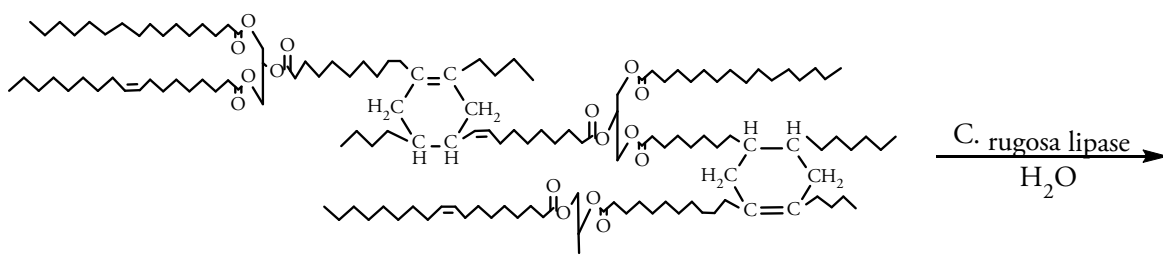

Bodied SBO

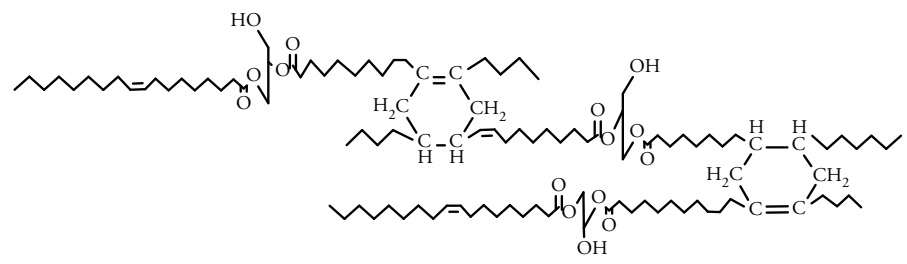

Hydrolyzed BSBO

Figure 6. Reaction Mechanism of a) Heat-Polymerization of Soybean Oil, and b) Hydrolysis of Bodied Soybean Oil by C. rugosa Lipase.

Lipase Immobilization. Immobilization of enzymes has been widely studied because of the advantages of immobilized enzymes over using free enzymes in biocatalysis. Immobilized enzymes possess improved storage, operational, thermal and conformational stabilities. Immobilization also allows for easier recovery for reuse (Anderson et al., 1998). Lipases which have been known to catalyze soy-based polyol production such as Pseudomonas $s p$. and Candida rugosa have been tested in different immobilized support material systems such $\mathrm{CaCO}_{3}$,
$\mathrm{CaSO}_{4} \cdot 2 \mathrm{H}_{2} \mathrm{O}, \mathrm{Ca}_{2} \mathrm{P}_{2} \mathrm{O}_{7}$, Celite, polyurethane foam, Eupergit ${ }^{\circ} \mathrm{C}$, bentotite, alginate beads, silica gel, porous glass surface, and many others (Kuncova et al., 2002; Yesiloglu, 2005; Knezevic et al., 2006; Rosu et al., 1997; Awang et al., 2007).

\section{CHEMICAL ROUTES}

The chemical route of polyol synthesis comprises the largest preparation methods for soy-based polyols. The initial step involves direct functionalization of 
soybean oil triglyceride to create: 1) hydroxyl-rich triglycerides, 2) high molecular weight oligomers with increased hydroxyl functionality, and 3) epoxidized triglycerides for a variety of ring opening reactions.

Aside from epoxidation, various methods have been used to produce the above properties for polyol synthesis. One method developed to produce soybased polyols with primary hydroxyls is ozonolysis. Ozonolysis is employed to cut double bonds to produce hydroxyls at the 9 position since all major unsaturated fatty acids have their first double bonds between 9 and 10 carbon. The synthesized soy-based polyols from ozonolysis has the functionality no larger than 3 (Tan, 2010).

Another method used to produce primary hydroxyls is hydroformylation followed by hydrogenation. The double bonds are first converted to aldehydes via catalyzed hydroformylation using synthetic gas (typically a 1:1 mixture of $\mathrm{CO}_{2}$ and $\mathrm{H}_{2}$ ), and then to hydroxyl groups via hydrogenation of aldehyde. A 95\% double bond to aldehyde conversion yield has been obtained using rhodium catalyst, whereas, $67 \%$ yield was observed using cobalt (Li, et al., 2015).

A process described by Zoran et al (2011) utilized a superacid catalyst for the cationic polymerization of soybean oil. In this study tetrafluoroboric acid (HBF4) available as $54 \%$ solution in diethylether was used as catalyst. Cationic polymerization of oils produces only triglycerides fatty acid hydrocarbon chains linked by various $\mathrm{C}-\mathrm{C}$ bonds, without carboxyl, aldehyde, ketone or hydroperoxide groups.

Epoxidation. New value-added products such as polyols can be produced from soybean oil because of the presence of reactive sites in the triglyceride molecule. The major reactive sites in a soybean oil molecule include the ester linkages and the double bonds on its fatty acids. Epoxidation is the chemical method of converting the double bonds of the SBO molecule into the more reactive oxirane or epoxide moiety by reaction with peracids or peroxides. In other words, epoxidation is characterized by epoxy ring formation followed by the ring opening to form a vegetable oil-based polyol with one or more secondary hydroxyl groups (de Souza et al., 2012). Epoxidized soybean oil has been used as a raw material for the synthesis of new polymers and derivatives or directly used in a variety of different polymer preparations (Kiatsimkul et al., 2006; Biresaw et al., 2008; Biswas et al., 2008; Dwan'Isa et al., 2003).

Epoxidation can be carried out using different chemical methods. Epoxidation of soybean oil is possible using peroxyacetic acid generated in situ in the presence of sulfuric acid as the catalyst. In this method, almost complete conversion of unsaturated carbon and negligible oxirane cleavage can be attained with an increase in the process temperature. Temperatures of $45^{\circ} \mathrm{C}, 65^{\circ} \mathrm{C}$, and $75^{\circ} \mathrm{C}$ have shown that an increase in the process temperature would increase the rate of epoxide formation (Cai et al., 2008).

Inorganic and metal catalysts can also be used to produce ESBO and epoxidized methyl esters. High yield conversion of soybean oil and soybean methyl ester double bonds into oxirane moieties were reported using hydrogen peroxide in dilute solution $(6 \mathrm{wt} \%)$ in the presence of an amorphous heterogeneous $\mathrm{Ti} / \mathrm{SiO}_{2}$ catalyst and tert-butyl alcohol. Highest yields of epoxidized olefins were obtained using a $\mathrm{H}_{2} \mathrm{O}_{2}$ : substrate molar ratio of 1.1:1. Ratios more than this were not effective for speeding up the reaction and could degrade the oxirane ring (Campanella et al., 2004).

Other effective catalysts used in the epoxidation of bulk soybean oil are acidic ion exchange resins. Acidic ion exchange resins haveporous structures which minimize side reactions such as the epoxy ring opening. In a study that generates an optimal yield of $91 \%$ conversion, $5.99 \%$ epoxide content in product used 0.5 mole of glacial acetic acid and 1:1 mole of hydrogen peroxide (30\% aqueous solution) per mole of ethylenic unsaturation. The reaction was performed in the presence of $5 \mathrm{wt} \%$ of the ion exchange resin at $75^{\circ} \mathrm{C}$ for $8 \mathrm{~h}$ (SinadinovicFiser et al., 2001). Another ion exchange resin in acid form (Amberlite IR-20) was effectively used as catalyst with in situ epoxidation of SBO carried out in toluene forming peroxoacetic and peroxoformic acids. Side reactionswere found to be minimal with peroxoacetic acid in the entire temperature range $\left(40,60,80^{\circ} \mathrm{C}\right)$ and higher with peroxoformic acid at $80^{\circ} \mathrm{C}$ (Petrovic et al., 2002).

In a separate study, a chlorinated KU-2 x 8 cation exchanger was found to be a highly active and stable catalyst for $\mathrm{SBO}$ epoxidation in the presence of $\mathrm{H}_{2} \mathrm{O}_{2}$ and propanoic acid. Results have shown that the cation exchanger catalyzes the formation of peroxypropionic acid exlusively and has no effect on the rates of oxidation of the double bond of soybean oil and epoxy ring opening. This effect improves the selectivity and efficiency of the epoxidation process (Gurbanov et al., 2005).

In another study, epoxidation was effectively performed using a catalytic biphasic system of methyltrioxorhenium (MTO) $-\mathrm{CH}_{2} \mathrm{Cl}_{2} / \mathrm{H}_{2} \mathrm{O}_{2}$. At an optimized reaction conditions (reactant ratio, time, 
and temperature) total double bond conversion and $95 \%$ selectivity were obtained in $2 \mathrm{~h}$ at room temperature. Tunable degrees of epoxidation are possible by changing the amounts of oxidant and MTO (Gerbase et al., 2002).

Epoxy Ring Opening. The cleavage of the oxirane rings obtained from the epoxidation of SBO through the chemical route opens new possibilities in finding new industrial uses of epoxidized soybean oil. Because of the high reactivity of the epoxy rings, a broad range of electrophilic and nucleophilic agents that may be prepared could pave the way to new chemical synthesis routes to develop new oleochemicals for many applications and uses.

A wide variety of different organic and inorganic reactants and catalysts were reportedly employed in the oxirane ring opening reactions of ESBO. In one study, ring opening reactions are carried out using low molecular weight alcohols such as methanol, 1,2-ethanediol and 1,2-propanediol as reactants in the presence of tetrafluoroboric acid as catalyst. The resulting soy-based polyol obtained from both methanol and 1,2-ethanediol had significant number of hydroxyl groups but the latter had primary hydroxyls which are more reactive than secondary hydroxyls promoting reactive activity of the polyol with isocyanates. The polyol obtained from 1,2-propanediol contained large numbers of hydroxyl groups which can hasten reactivity with isocyanates in polyurethane applications (Dai et al., 2009). Furthermore, Li. et al. (2015) also synthesized two bio-based polyols from ESBO using glycolic and lactic acid. The resulting polyols had larger molecular weights indicating significant oligomerizations of triglycerides. Another study
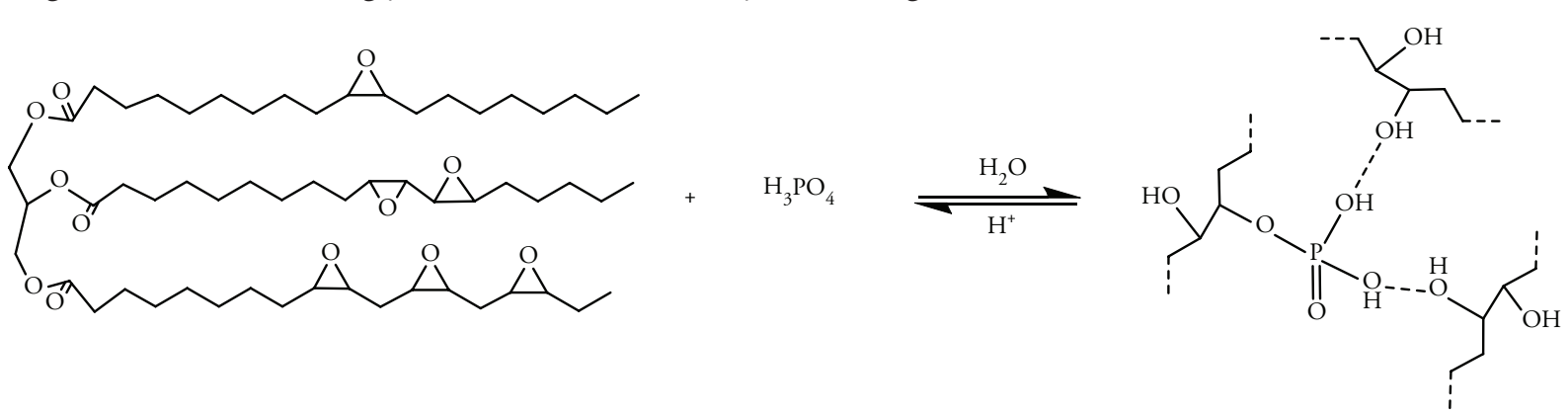

ESBO $o$-Phosphoric acid

Figure 7. Reaction Mechanism of Phosphate Ester Formation.

Phosphoric acid does not only catalyze ring-opening reaction of ESBO with water but also chemically combine to become part of the polyol product (Figure 7). Much of the work done to produce soybean oil phosphate ester polyols used water and significant amount of polar solvents such as 2-propyl alcohol, methanol, to obtain high hydroxyl functionality while keeping the final acid values low (Guo et al., 2007; Guo et al., 2006; Mannari and Massingill, 2006; Lin et al., 2008).

made use of boron trifluoride diethyl etherate ring opening polymerization of ESBO. The resulting polymerized epoxidized soybean oil indicated highly crosslinked polymers with glass transition temperatures ranging from -16 to $-48{ }^{\circ} \mathrm{C}$, showing hermal stability at temperatures up to $220^{\circ} \mathrm{C}$. These by chemical modification by hydrolysis and will find applications in personal care and health care areas

Other types of products obtained from the cleavage $\mathrm{BO}$ oxirane rings are called soy-based phosphate in the formation of phosphate esters. Phosphoric acid $\left(o-\mathrm{H}_{3} \mathrm{PO}_{4}\right)$ has been extensively used in the preparation of a series of soybean oil phosphate esters for rigid polyurethanes, coatings, surfactants et al., 2007; Guo et al., 2006; Zhong et al., 2001). Soy-based polyols having tunable hydroxyl content and phosphate ester functionality are possible by controlling the type and amount of polar solvent and phosphoric acid content added to the reactants (Guo et al., 2007). 
scheme (Figure 8). An epoxy ring reacts with EG to form an ether alcohol. In the bigger scheme, simultaneous conversion of the reacting species into ether alcohol will effect a complexation between ESBO and EG, thus the polymerization. The resulting increase in viscosity and consumption of oxirane oxygen content were mainly attributed to this complexation which is suggested to be the main product (Lubguban et al., 2009).
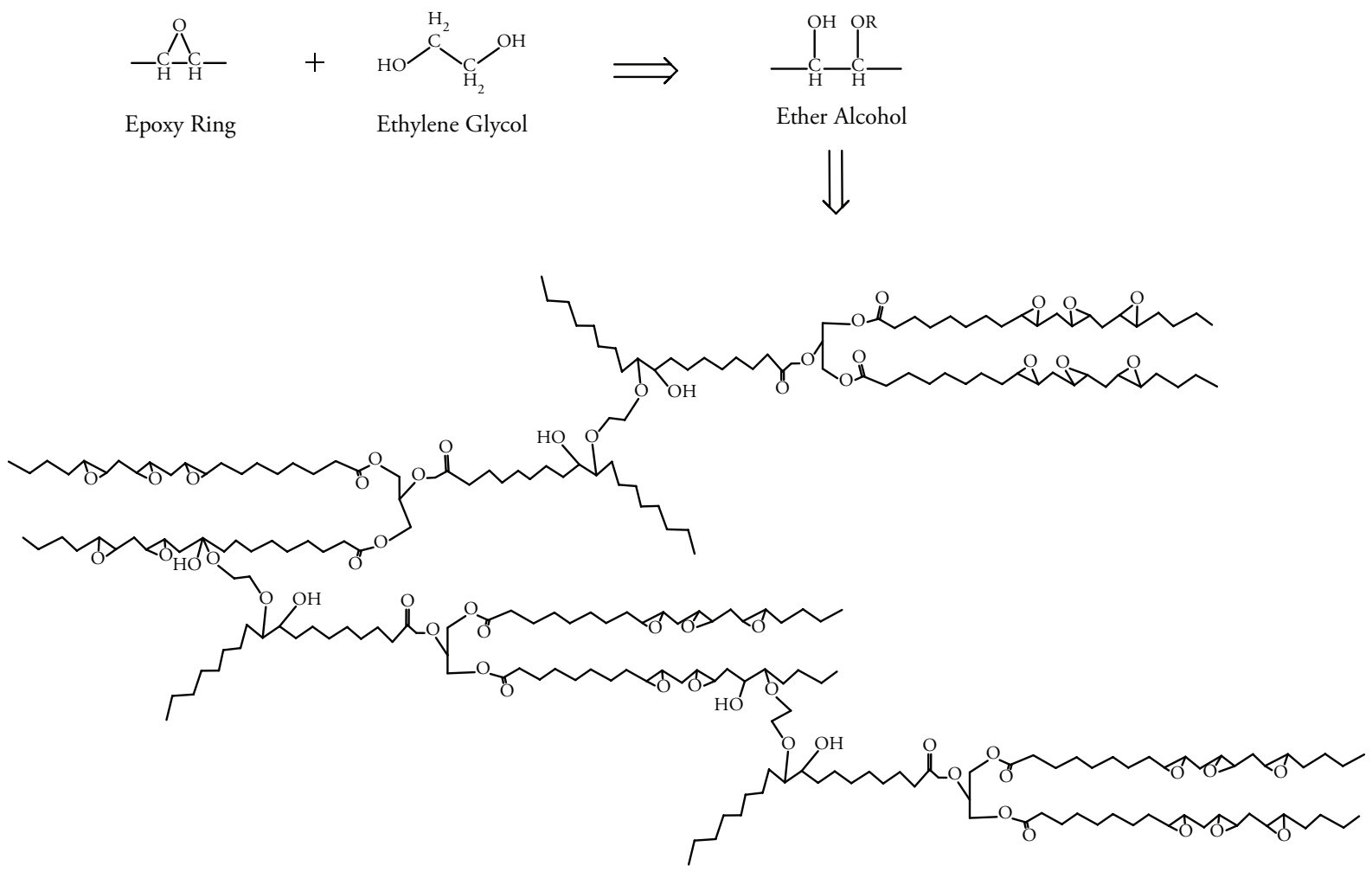

ESBO-EG Complex

Figure 8. Reaction Scheme of ESBO-EG Complex.

to polyurethanes will affect the physicochemical properties of the final product (Guo et al., 2000).

Glycerolysis. The direct use of glycerol in the functionalization of SBO to obtain a soy-based polyol with homogeneous or uniform chemical properties is a straightforward and economical (Lubguban et al., 2009). The polyol produced from this twostep process starts with the heat polymerization (bodying) of SBO. This promotes the crosslinking of acylglycerols, generally through Diels-Alder reaction, resulting in a product with an increased viscosity and high molecular weight distribution which is desirable in later urethane formulations due to larger amounts of polyol engaged in the reaction (Lubguban et al., 2009). Glycerolysis of bodied SBO (BSBO) proceeds at temperatures greater than 200 ${ }^{\circ} \mathrm{C}$ in a one-pot transesterification process of BSBO and pure glycerol. The extent of polymerization and quantity of glycerol added during the process
Different other methods have been investigated to convert the epoxy groups in ESBO to hydroxy groups. These methods include catalytic hydrogenation, halogenation or reaction with hydrochloric or hydrobromic acid, and acid-catalyzed ring opening reaction with methanol to produce methoxylated polyol, or water to produce vicinal hydroxy groups. These reactions would produce a range different polyol structures which when converted 
with other hydroxyl supplying chemical agents.

Air Oxidation. Oxidation of soybean oil oxidation is an important issue several areas in human health, food spoilage, and in the properties of monomer feedstocks. Air oxidation of soybean oil involves free radical intermediates through the abstraction of allylic hydrogens and the subsequent formation of a delocalized free radical which reacts with ambient oxygen and other triglycerides to form polyols (Fornof et al., 2006).

Air oxidation is an inexpensive and simple reaction method for the production of high hydroxyl number soy-based polyols. In a typical procedure, soybean oil heated to the appropriate temperature $\left(110^{\circ} \mathrm{C}\right)$ and air $\left(25 \mathrm{~L} \mathrm{~min}^{-1}\right)$ is delivered to the sample using a dispersion tube for several days and allowed to cool to room temperature after the reaction is complete. Several stages of chemical changes happen in the process of air oxidation. The first stage is described as the period when insignificant change in the hydroxyl number of the soybean oil occurs. It is proposed that natural antioxidants present in the raw SBO sample are consumed with the formation of peroxide. The second stage is marked by an increase in hydroxyl number due to the formation and subsequent decomposition of peroxides. In the last stage, free radical crosslinking occurs and gel formation. Temperature and reaction time play an important role on the extent of crosslinking and hydroxyl content of the final polyol products (Fornof et al., 2006).

Soy-based polyols obtained from air oxidation of raw $\mathrm{SBO}$ can be processed further or catalyzed to obtain high hydroxyl number polyols. Normally, polyols with hydroxyl numbers $<110 \mathrm{mg} \mathrm{KOH} / \mathrm{g}$ can be synthesized via air oxidation (up to 5 days processing, no catalysts). Different methods of hydroxylation and catalytic air oxidation processes will increase the hydroxyl functionality of soy-based polyols produced from non-catalytic air oxidation described above (Fornof et al., 2006; Pechar et al., 2006). Induced air oxidation of soybean oil was also shown to produce a significant increase in the number of hydroxyl groups. Moreover, it resulted in higher molecular heterogeneity and therefore a broadening of the range of melting temperatures (Ourique, et al., 2015).

Hydroformylation. Hydroformylation is another alternative process to prepare soy-based polyols wherein the double bonds of SBO are converted to aldehydes using metal catalysts containing cobalt or rhodium. This process involves the reaction of hydrogen and carbon monoxide with double bonds to give aldehydes. The resulting aldehydes may subsequently be hydrogenated to triglyceride polyols using Raney nickel as catalyst. Hydrogenation steps are usually conducted at $180{ }^{\circ} \mathrm{C}$. Ligand-modified rhodium-catalyzed hydroformylation of $\mathrm{SBO}$ can be performed at a temperature range of $90-110^{\circ} \mathrm{C}$ and $14 \mathrm{MPa}(2000 \mathrm{psi})$ of total syngas $\left(\mathrm{H}_{2} / \mathrm{CO}=\right.$ $1: 1)$ pressure. Cobalt-catalyzed hydroformylation can be conducted at $120^{\circ} \mathrm{C}$ and $28 \mathrm{MPa}(4000 \mathrm{psi})$ of total syngas pressure. Depending on the reaction conditions and the type of catalysts used, polyols of different degrees of conversion (up to 95\%) can be produced (Guo et al., 2002; Kandanarachchi et al., 2002; Petrovic et al., 2008). In a different study, the use of nickel as a catalyst a higher efficiency in producing polymers with higher viscosity in a shorter time than when comparing with reactions without catalyst (Mello, et al., 2015).

Ozonolysis. Most chemical methods involved in the conversion of SBO into high hydroxyl content polyols are either too costly, inefficient, or yield secondary alcohols, which are less reactive than the primary alcohols. Ozonolysis occurs between ozone and the unsaturations of a fatty acid hydrocarbon chain to form an intermediate ozonide ring. Afterwards, the unstable ozonide ring is opened and chain scission occurs, yielding aldehyde or ketone groups that are subsequently reduced to primary hydroxyl groups (de Souza et al., 2012). Catalytic ozonolysis is shown to produce primary soy-based polyols which is prepared by passing ozone through a solution of soybean oil and ethylene glycol in the presence of an alkaline catalyst or reducing agents $\left(\mathrm{NaOH}\right.$, pyridine, 4-DMAP, $\mathrm{CaCO}_{3}$, or $\left.\mathrm{NaBH}_{4}\right)$. The ozone cleaves and oxidizes the double bonds in the soybean oil to produce the ozonide intermediates. In conventional ozonolysis, these intermediates are spontaneously reduced to aldehydes and carboxylic acids. With the addition of ethylene glycol, the ozonide intermediates react with the hydroxyl group of EG to form an ester linkage with a terminal hydroxyl group (Tran et al., 2005).

The molecular weight and hydroxyl functionality of the polyol product can be adjusted or controlled by using triols or other low molecular weight polyols other than ethylene glycol. To control the polyether chain lengths of the product, catalyzed ozonolysis with polyethylene glycols can be used. These polyol products with a wide range of properties give flexibility as to its intended use such as polyurethanes with different physicochemical properties (Tran et al., 2005).

Dihydroxylation. As an alternative to petroleumbased process, a novel method of direct hydroxylation of soybean oil is employed using $\mathrm{OsO}_{4}$ as catalyst and NMO (4-methylmorpholine 
$\mathrm{N}$-oxide) as oxidant. This one-step dihydroxylation process replaces the traditional two-step methods, including epoxidation and then hydroxylation. The major advantages of this approach include: two hydroxyl groups can be readily added to one double bond, replacing conventional two-step methods by an epoxidation step and then a ring opening step; a wide range of hydroxyl numbers can be obtained via varying catalyst loadings; and the reaction can be performed at room temperature (Sun at. al., 2012).
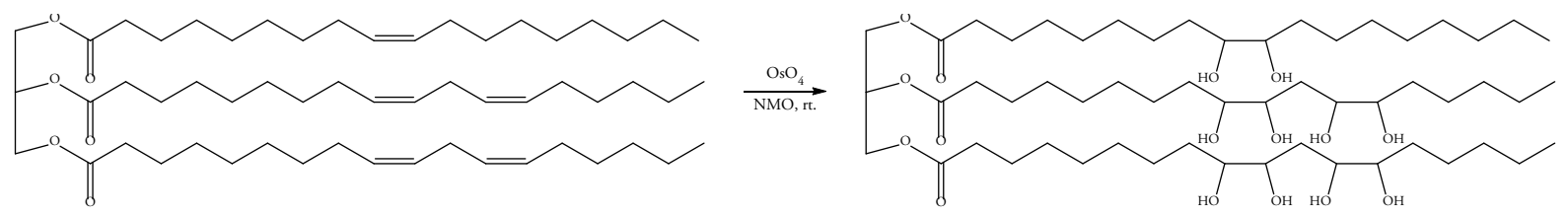

Figure 9. $\mathrm{OsO}_{4}-$ Catalyzed Dihydroxylation of Soybean Oil.

\section{SOY-BASED POLYURETHANES}

The functionalized soybean oil using the enzymatic and chemical reaction routes to generate soy-based polyols are largely tested and used commercially for the production of polyurethane foams, both rigid and flexible, and other elastomeric products. These soybased polyurethane products have shown properties comparable with petroleum-based formulations ( $\mathrm{Tu}$ et al., 2007; Tu et al., 2008).

Polyol Properties for Polyurethane Applications. Preliminary characterization of soy-based polyols is necessary because it dictates the physicochemical properties of the final PU products. The most important properties include acid number, hydroxyl number and viscosity. Acid and hydroxyl numbers are needed to calculate the amount of isocyanate needed for urethane reaction. The acid number is defined as the amount in milligrams of potassium hydroxide required to neutralize the acid present in one gram of a polyol sample (usually present as acid residuals in the polyol). Typical values of acid numbers in commercially-available polyols are less than $10 \mathrm{mg} \mathrm{KOH} / \mathrm{g}$ sample. Low acidity in polyols is desired because high acid number polyols tend to neutralize the urethane formulation catalysts and may react with isocyanate to compete with hydroxyls in the urethane formation (Kiatsimkul et al., 2007). Hydroxyl number is a measure of the amount of reactive hydroxyl groups available for reaction. This value is determined using a wet analytical method and is reported as amount in milligrams of $\mathrm{KOH}$ equivalent to the hydroxyl groups found in a gram of a polyol sample. Soy-based polyol, with high hydroxyl value, contributes imparts properties to $\mathrm{PU}$ foam such as superior tensile and higher elongation, but lower compressive strength and modulus. Nonetheless, biofoams made with high hydroxyl valued soy-based polyol have smaller and better distributed cell size than that using low hydroxyl soy-based polyol. Soy-based polyol with high hydroxyl value also contributes the bio-foam with thinner cell walls compared to that with low hydroxyl value (Gu et al., 2012).
Viscosity is considered an important physical property of the polyol. It indicates the degree of oligomerization of the reactants and therefore increases the average molecular weights of the polyols produced which have significant impact in later PU formulations (Herrington et al., 1997). Polyol viscosities are also indicative of product workability especially in mixing big batches in either pilot plant or large-scale production. A study also reports that foams made from high viscosity $(21,000-31,000$ cP) soy-polyols exhibited similar or superior densitycompressive strength properties to the control foam made from 100\% VORANOL-490 (Hongyu Fan, 2012).

Polyurethane foam properties can also be improved through addition of nanocomposites or other additives. Wanga (2014) studied the effect of adding raw and silylated palygorskite (R-PAand S-PA) on the properties of soy polyol-derived polyurethane (PU) nanocomposites. Resulting PU nanocomposites showed a significant improvement on the storage modulus and glass transition temperature. Moreover, tensile tests showed that both the PA has a prominent reinforcement effect on PU.

Rigid Foams. The formation of rigid polyurethane foams follows the general PU-forming reaction scheme (Figure 3), mainly, the reaction of alcohol with two or more reactive hydroxyl functional groups per molecule (diols or polyols) and isocyanates that have more than one isocyanate group per molecule (diisocyanate or polyisocyanate). Rigid foam formulations typically require a high hydroxyl number in the range of $400-500 \mathrm{mg} \mathrm{KOH} / \mathrm{g}$ to obtain the necessary rigidity (Lubguban et al., 2009).

Rigid PU foam is mostly used in thermal insulation and packaging due to its low thermal conductivity, excellent strength, and higher weight-carrying capacity. While most of the rigid foams on the market are based on polypropylene oxide, soy-based polyols have been tested and commercially produced due to the comparability of the soy-based PU foam's mechanical and thermoinsulating properties to 
that of petroleum-based foams (Tu et al., 2007; Guo et al., 2000). Different methods are tested to produce soy-based rigid PU foams with comparable properties to that of petroleum-based polyols. The goal is to replace the latter wholly or partly in PU formulations. Most of the soy-based PU products currently produced use a mixture of both soy-based and petroleum-based polyols. The ultimate goal in most soy-based PU research is directed towards using 100\% soy-based polyols in PU formulations.

A typical rigid PU foaming process can be performed using a mixing vessel equipped with a high speed impeller to achieve adequate dispersion of the B-side components. The amount of polyol mixture (soybased and petroleum-based), catalysts, surfactant, and blowing agent (water) are determined by weight and added into the mixing vessel mixed at 3450 rpm for 10-15 s or until a homogeneous mixture is obtained. The mixture is degassed for $120 \mathrm{~s}$ after which the polymeric MDI (A-side-isocyanate source) is added. The PU formation process and parameters can be optimized to produce rigid foams (Tu et al., 2007).

Rigid water-blown soy-based polyurethane foams can be obtained by replacing $0-50 \%$ of the petroleumbased polyol in the B-side of foam formulation by ESBO. For rigid water-blown PU foam, density, compressive strength, and thermal conductivity are important physicochemical properties that would indicate material quality for its intended use as rigid foam. Established standards can be used to measure these properties. For this particular formulation, it appears that up to $20 \%$ of petroleum-based polyol could be replaced by ESBO in rigid PU foams without compromising the properties (Tu et al., 2008). Hongyu Fan (2012), meanwhile, reports up to $50 \%$ of petroleum-based polyol can be replaced to achieve desired thermal conductivities. The new formulation resulted in a $30 \%$ reduction of isocyanate use.

Factors Affecting PU Foam. There are various factors that can affect the structure of the rigid foams. These factors include polyol functionality and viscosity, isocyanate index, amount of catalysts and surfactants used, and blowing agents. In comparison, petroleumbased polyol's structure and functionality is far more superior than soy-based polyol due to the former's mainly uniform and linear structures (with methyl group branches) with terminal hydroxyls which are three times more reactive than secondary alcohols (Powers, 1950; Adams and Powers, 1944). For example, a petroleum-based triol (Figure 9) has all its hydroxyls located in a terminal position making it highly reactive with any available isocyanate group in PU formation.

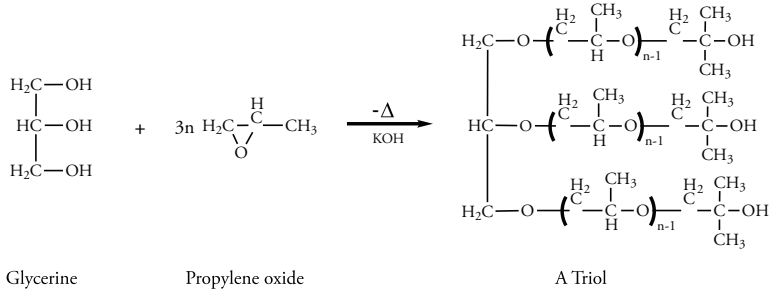

Figure 10. A Triol Synthesis Using Trifunctional Glycerine Initiator and Propylene Oxide.

This property makes petroleum-based polyols highly desirable in the polyurethane industry. A faster reaction and higher conversion rate would result in denser and stronger crosslinked three-dimensional PU networks that eventually gives a higher foam density and volume. Such PU rigid foams have higher compressive strength and density. The thermal conductivity of rigid PU foamis also greatly affected by the rate of reaction. A faster reaction rate expected with primary hydroxyls results in a stronger three-dimensional PU network capable of holding up most of the carbon dioxide evolved in the reaction of isocyanate and water. Secondary hydroxyl group which composed most of biobased polyols tends to proceed in a slower reaction rate with isocyanate resulting in a weaker polymer network and increased number of open cells. These formed cells are susceptible to air convection and escape of carbon dioxide, both of which contribute to a higher thermal conductivity (Herrington et al., 1997; Szycher, 1999).

Soybean oil MG has been used as a highly reactive polyol for PU rigid foams due to its high primary hydroxyl group content in addition to a secondary hydroxyl group. Compared with polyols made from hydroxylated SBO and methanol-SBO, soybean oil MG generates smaller and well-organized foam cell shapes which can be attributed to the dominance of primary hydroxyl reaction with isocyanate (Campanella et al., 2009). At a higher reaction rate, the average cell size of the foams tends to be uniform and smaller (Campanella et al., 2009).

A catalyst has a significant effect on the final PU foam product as it accelerates and balances the competing reactions that occur in the PU-forming process. The foam structure sensitively depends on the amount of catalyst added. With the catalyst added at less than the required amount, gas formation rate is higher than the cure rate which eventually collapses the foam structure. This explains that a higher dosage of the catalyst is indicated to give a relatively rigid foam structure (Banik and Sain, 2008). The amount of catalyst added should be determined to balance these competing reactions and optimally expand the foam with the desired density and uniformity of cell structure (Campanella et al., 2009). Surfactant 
is added to the PU foam formulation because it helps stabilize the growing cells in the foam-forming process by stabilizing he gas bubbles formed during nucleation (Campanella et al., 2009).

Water is widely used as the reactive blowing agent in PU foam formulations. Adding more water in the reaction mix produces more $\mathrm{CO}_{2}$ during the foam formation resulting in lower final density due to foam volume expansion, thinner foam cell walls, and larger foam cells. Adding the right amount of water produces more uniform and stable cell structure (Campanella et al., 2009). Increased concentrations of water in a given polyol-isocyanate combination tends to have a relative flexibility due to an enhanced foaming on the polymer matrix (Banik and Sain, 2008). As the compressive strength of PU foams increases continuously with increasing the amount of water, foam strength can be adjusted by varying the water quantity in the formulation without sacrificing the thermoinsulating property (Guo et al., 2000).

The type of isocyanate used in the PU foam formulation also significantly affects the cellular structure in terms of cell size, uniformity, and the cell morphology (open- or closed-type). The foams produced with toluene diisocyanate (TDI) are closed cells while MDI or modified MDI give open cell foam structures. Foams produced from MDI are more rigid with a slower reaction rate than that of TDI (Campanella et al., 2009).

The isocyanate index of the foam formulation also greatly affects the final structure of the soy-based rigid PU foam. Varying the isocyanate index of the formulation from 110 to 350 it is shown that soy-based polyisocyanurate foams displayed better thermal stability, lower flammability, higher rigidity (modulus), and higher compression strength than those based on the propylene oxide polyols of the same molecular weight and functionality (Javni $e t$ al., 2004).

Flexible Foams. Flexible PU foams are one of the most versatile materials being produced from PUforming reaction. It has It has been used widely in various applications such as for cushioning in furniture, mattresses, automobiles, and even clothing. Flexible PU foams are prepared in a similar manner as the rigid PU foams but certain catalysts and surfactants are used to enhance its properties. Flexible foams are open cell materials that allow free movement of air between the foam cavities. Particularly important physical and mechanical properties for the application of flexible foams are their compression-strain behavior including density (commonly $13-80 \mathrm{~kg} / \mathrm{m}^{3}$ ), set and recovery, glass transition, cellular morphology, air flow characteristics, flex fatigue, tear strength, resilience, combustibility, etc.

Soy-based polyols for use in flexible PU formulations have been tested and have shown successful results. Most soy-based flexible PU foams use a mixture of soy-based and petroleum-based polyols and the desire to incorporate most or all of the latter has spurred more research (Das et al., 2009).

Epoxidized soybean oil has been used to replace petroleum-based polyols up to $20 \%$ in the production of flexible PU foams. The density and $50 \%$ compression deflection properties were similar or better than foams prepared with $100 \%$ petroleumbased but resilience and 50\% constant deflection compression properties were inferior ( $\mathrm{Tu}$ et al., 2008). This shows that increasing the percentage of replacement with the soy-based polyol material in the formulation compromises the physical and mechanical properties of the final PU flexible foam product. The study of the optimization or control of the factors affecting soy-based polyol and PU foam preparation is necessary to achieve the desired product.

\section{REDUCTION OF ISOCYANATE USE}

A potential focus for future research is to reduce isocyanate use either by 1) increasing reactivity, 2) increasing the hydroxyl equivalent weight, or 3) synthesizing soy-based polyols that mimic the chemical structure of the urethane linkage of the polyol and isocyanate. Furthermore, other researches also explored the possibility of producing PU foams without the use of toxic isocyanate.

\section{Increasing Reactivity and Hydroxyl Equivalent} Weight. Finding an effective enzymatic or chemical method to functionalize SBO to better achieve reactivity with isocyanate has always been a challenge in soy-based polyol research. Synthetic methods that generate primary hydroxyls in the final soy-based polyols are still being developed and optimized. Enzymatic hydrolysis using C. rugosa has been shown to produce polyols with primary hydroxyl groups (Kiatsimkul et al., 2007) present an economic and operational drawback due to its high cost and low thermal and conformational stabilities. Immobilization improves these limitations to a certain extent. Other methods that are known to generate primary hydroxyls are SBO-MG and ozonolysisprocessed polyols mentioned in Section 5.

High equivalent weight soy-based polyols can be achieved by polymerization and functionalization of SBO acylglycerols. The objective is to increase the 
average hydroxyl equivalent weight of the soybean oil to engage much of the mass of the crosslinked soy-based polyol complex while reacting its hydroxyl groups with the reactive $-\mathrm{NCO}$ groups of the isocyanates. Examples of high hydroxyl equivalent weight soy-based polyols are glycerolized bodied soybean oil, glycolysis oligomers, and soy phosphate esters (Lubguban, et al., 2009; Guo et al., 2006).

Urethane Bond Mimics. MDI has a central benzene ring attached to $-\mathrm{NCO}$ and $-\mathrm{CH}_{2}$ groups while soy-based urethane linkage has polymeric MDI attached to the reactive sites of the polyol. A search for reactants that would provide similar structure in the polyols will be a worthwhile pursuit in product development.
Non-Isocyanate Polyurethane. Recent studies has showed that polyurethane can be prepared without toxic isocyanate. One possible method is to use reaction of cyclic polycarbonates with amines. Soybean oil (SBO) especially epoxidized SBO (ESBO) can be used for preparation of nonisocyanate polyurethanes by this route. ESBO is used as a starting chemical that reacts with carbon dioxide in the presence of a catalyst to produce carbonated SBO (CSBO) (Javni et al., 2012). The synthetic route is shown in Figure 11 (Bahr and Mulhaupt, 2012).

Reactions of cyclic carbonates and nucleophiles proceed in two ways: alkylation and ring opening. Weak nucleophiles such as phenol, thiophenol or<smiles>[R]C1OC1CC(=O)OCC(COC(=O)CC1OC1[R])OC(=O)CC1OC1[R]</smiles>

Figure 11. Synthetic Route for NIPU Formation.

aniline are alkylated and $\mathrm{CO}_{2}$ split off. Stronger nucleophiles such as primary alkylamines react with cyclic carbonates to promote ring opening and formation of N-hydroxy urethanes without loss of carbon dioxide. The reactivity depends upon the carbonate ring size (Bahr and Mulhaupt, 2012). The formation of polyurethanes from the CSBO and diamines is illustrated in Figure 12 (Javni et al., 2012).

Reaction of ESBO with carbon dioxide in the presence of tetrabutylammonium bromide (TBAB) lead to the formation of CSBO. Conversion of epoxy groups to cyclic carbonate groups was $98 \%$ and residual EOC was $0.15 \%$. CSBO had four cyclic carbonate groups per soy soil molecule and a viscosity of 41.9 Pa.s. The CSBO was mix with amine. The reaction of a cyclic carbonate with an amine produces urethane and the hydroxyl group.
Nonisocyanate polyurethanes prepared from CSBO and aliphatic diamines had relatively low tensile strength compared to conventional PU (Javni et al., 2012).

\section{Modelling of the Polyurethane Production} Process. Research on soy-based polyurethane production revolves around the goal of switching from traditional petroleum-based raw materials to bio-based sources. Through modelling, researchers can predict resulting properties for PU foam production which can easily be validated through characterization. Modelling investigates both the physical and chemical processes which are defined by ordinary differential equations.

Zhao, et al. (2013) studied the effect of catalyst loading on the PU box foaming process using MATLAB. Factors such as polyol type, catalyst type 

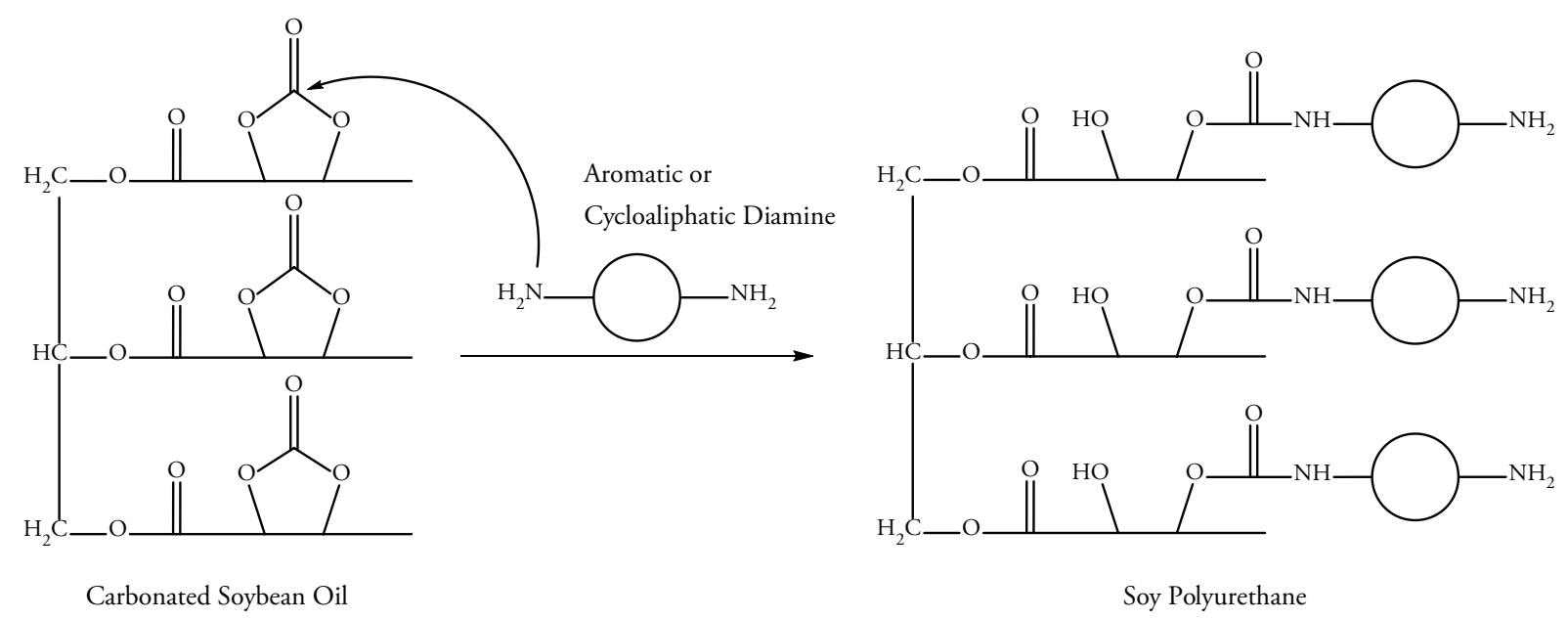

Figure 12. Formation of Polyurethanes from the CSBO and Diamines.

and reaction temperatures were taken into account. The model was able to predict the performance of foams with varying combinations of catalysts, chemical blowing agents, isocyanates, physical blowing agents, and polyol. Suppes, et al.(2013) also used MATLAB to model temperature profiles of single-polyol polyurethane formulations and was able to accurately predict temperature profiles of mixtures based on pure component kinetic parameters. The final densities of foams were also predicted using modelling. It was found out that the inefficient use of blowing agent results from loss of physical blowing and evaporation for blowing agents with boiling points between $25^{\circ} \mathrm{C}$ and $80^{\circ} \mathrm{C}$ (Shen, et al., 2013). The effects of primary, secondary, and hindered-secondary hydroxyl groups on the reaction and the temperature profile on polyurethane gels was also investigated (Ghoreishi, 2013). This model allows researchers to predict polyol properties based on the type of hydroxyl group, and not the type of polyol.

\section{CONCLUSIONS}

Polyols derived from soybean oil are alternative materials for polyurethane applications including rigid and flexible foams. Soy-based polyols are important industrial prepolymeric materials that use renewable resources and with isocyanates they produce polyurethanes (PU) foams that can compete in many aspects with polyols derived from petrochemicals. Their impact in the future of polyurethane chemistry will be significant.

The preparation of soy-based polyols synthesized from enzymatic biocatalysis is a fairly new technology that has the advantage of high lipase selectivity with the potential for yielding primary hydroxyls which are known to be highly reactive, thus, increasing hydroxyl functionality for polyurethane production. Although the use of $C$. rugosa lipase is economical in some aspects (less organic solvents, low temperature process) and leaves less carbon footprint, the prices of enzymes are expensive. Enzyme immobilization is necessary to improve storage stability, recovery ability, and length of hydrolytic activity.

An alternative to enzymatic process using BSBO was described in one chemical route described in this study. Bodying of the soybean oil is an effective method to increase the average equivalent weight of the final polyol. This was shown in the lower extractable content of the material compared to non-bodied samples. Functionalization was made possible by one-pot process of glycerol transesterification attaching hydroxyl-functionality to $\mathrm{BSBO}$, thus, increasing the average hydroxyl functionality. Other chemical methods to increase equivalent weight and hydroxyl functionality in soybean oil used epoxy-ring opening reactions and esterification methods. Present and future researches aim to investigate more reaction routes to increase both equivalent weight and hydroxyl functionality in soy-based polyols.

\section{REFERENCES}

Adams HE, Powers PO. Mechanism of heat bodying linseed oil. Ind Eng Chem. 1944 Dec; 36(12):11241127.

Andjelkovic DD, Valverde M, Henna P, Li F, Larock RC. Novel thermosets prepared by cationic copolymerization of various vegetable oils - synthesis and their structure-property relationships. Polymer. 2005; 46:9674-9685.

Anderson EM, Larsson KM, Kirk O. One biocatalyst - many applications: The use of Candida antarctica $\beta$-lipase in organic synthesis. Biocatal Biotransfor. 1998; 16:181-204. 
Awang R, Ghazuli MR, Basri M. Immobilization of lipase from Candida rugosa on palm-based polyurethane foam as a support material. Am J Biochem Biotech. 2007; 3(3):163-166.

Bahr M, and Mulhaupt R. Linseed and soybean oilbased polyurethanes prepared via the non-isocyanate route and catalytic carbon dioxide conversion. Green Chemistry. 2012; 14:483.

Bakhshi, Hadi, et al. Synthesis and characterization of antibacterial polyurethane coatings from quaternary ammonium salts functionalized soybean oil based polyols. Mater Sci Eng C. 2013; 33(1): 153-164.

Bandyopadhyay-Ghosh S. Synthesis of Soy-Polyol by Two Step Continuous Route and Development of Soy-Based Polyurethane Foam. J Polym Environ. 2010; 18:437-442.

Banik I, Sain MM. Water blown soy polyol-based polyurethane foams of different rigidities. J Reinf Plast Comp. 2008; 27(4):357-373.

Bornscheuer UT, editor. Enzymes in lipid modification. New York: Wiley-VCH; 2000.

Bjorkling F, Godtfredsen SE, Kirk OJ. Lipasemediated formation of peroxycarboxylic acids used in catalytic epoxidation of alkenes. Chem Soc Chem Commun. 1990 Jun; 1301-1303.

Biresaw G, Liu ZS, Erhan SZ. Investigation of the surface properties of polymeric soaps obtained by ring-opening polymerization of epoxidized soybean oil. J Appl Polym Sci. 2008 May; 108(3):19761985.

Biswas A, Sharma BK, Willett JL, Advaryu A, Erhan SZ, Cheng HN. Azide derivatives of soybean oil and fatty esters. J Agr Food Chem. 2008 Jul; 56(14):5611-5616.

Cai C, Dai H, Chen R, Su C, Xu X, Zhang S, Yang L. Studies on the kinetics of in situ epoxidation of vegetable oils. Eur J Lipid Sci Technol. 2008; 110:341-346.

Campanella A, Baltanas MA, Capel-Sanchez MC, Campos-Martin JM, Fierro JLG. Soybean oil epoxidation with hydrogen peroxide using an amorphous $\mathrm{Ti} / \mathrm{SiO}_{2}$ catalyst. Green Chem. 2004; 6:330-334.

Campanella A, Bonnaillie LM, Wool RP. Polyurethane foams from soyoil-based polyols.
J Appl Polym Sci. 2009 Feb; 112:2567-2578.

Chengshuang Wanga, LD. Soy polyol-based polyurethane modified by raw and silylated palygorskite. Ind Crops Prod. 2014; 57:29-34.

Debruyne I. Novel soybean oil products for a healthier nutrition - Recent developments, market introduction and targeted commercialization. Lipid Tech. 2007 Jun; 19(6):128-131.

Dwan'Isa JPL, Mohanty AK, Misra M, Drzal LT, Kazemizadeh, M. Novel biobased polyurethanes synthesized from soybean phosphate ester polyols: thermomechanical properties evaluations. J Polym Environ. 2003 Oct; 11(4):161-168.

Dai H, Yang L, Lin B, Wang C, Shi G. Synthesis and characterization of the different soy-based polyols by ring opening of epoxidized soybean oil with methanol, 1,2-ethanediol and 1,2-propanediol. J Am Oil Chem Soc. 2009 Mar; 86(3):261-267.

Das S, Dave M, Wilkes GL. Characterization of flexible polyurethane foams based on soybean-based polyols. J Appl Polym Sci. 2009 Apr; 112(1):299308.

Desroches M, Escouvois M, Auvergne R, Caillol S, Boutevin B. From Vegetable Oils to Polyurethanes: Synthetic Routes to Polyols and Main Industrial Products. Polymer Reviews, Taylor \& Francis, 2012, 52 (1), pp.38.

Desroches, Myriam, et al. From vegetable oils to polyurethanes: synthetic routes to polyols and main industrial products. Polymer Reviews 52.1 (2012): 38-79.

Erhan S, Sheng Q, Hwang HS. Volatile by-products during heat polymerization of soybean oil. J Am Oil Chem Soc. 2003; 80(2):177-180.

Erhan S, Bagby M. Polymerization of vegetable oils and their uses in printing inks. J Am Oil Chem Soc. 1994; 71:1223-1226.

Erhan S, Bagby M, Nelsen T. Drying properties of metathesized soybean oil. J Am Oil Chem Soc. 1997; 74:703-706.

Farhoosh R, Einafshar S, Sharayei P. The effect of commercial refining steps on the rancidity measures of soybean and canola oils. Food Chem. 2009 Jan; 115(1):933-938.

Falkenburg L, DeJong WM, Handke D, Radlove S. Isomerization of drying and semi-drying oils: The 
use of anthraquinone as a conjugation catalyst. J Am Oil Chem Soc. 1948; 25:237-243.

Fregolente P, Fregolente L, Pinto G, Batistella B, Wolf-Maciel M, Filho R. Monoglycerides and diglycerides synthesis in a solvent-free system by lipase-catalyzed glycerolysis. Appl Biochem Biotechnol. 2008 Feb; 146:165-172.

Fu X, Zhu X, Gao K, Duan J. Oil and Fat Hydrolysis with Lipase from Aspergillus sp. J Am Oil Chem Soc. 1995; 72(5):527-531.

Fornof AR, Onah E, Ghosh S, Frazier CE, Sohn S, Wilkes GL, Long TE. Synthesis and characterization of triglyceride-based polyols and tack-free coatings via the air oxidation of soy oil. J Appl Polym Sci. 2006 Feb; 102:690-697.

Gu R, Konar S, Sain M. Preparation and Characterization of Sustainable Polyurethane Foams from Soybean Oils. J Am Oil Chem Soc. 2012; 89:2103-2111.

Gurbanov M, Chalabiev C, Mamedov B, Efendiev A. Epoxidation of soybean oil in the course of cooxidation with hydrogen peroxide in the presence of propanoic acid and chlorinated KU2x8 cation exchanger. Russ J Appl Chem. 2005 Jun; 78(10):1678-1682.

Gerbase A, Gregório J, Martinelli M, Brasil M, Mendes A. Epoxidation of soybean oil by the methyltrioxorhenium- $\mathrm{CH}_{2} \mathrm{Cl}_{2} / \mathrm{H}_{2} \mathrm{O}_{2}$ catalytic biphasic system. J Am Oil Chem Soc. 2002 Feb; 79(2):179-181.

Ghoreishi, R., Zhao, Y., Suppes, G.J. Reaction Modeling of Urethane Polyols Using Fraction Primary Secondary, and Hindered-Secondary Hydroxyl Content. J Appl Polym Sci. 2013.

Guo Y, Hardesty J, Mannari V, Massingill J. Hydrolysis of epoxidized soybean oil in the presence of phosphoric acid. J Am Oil Chem Soc. 2007; 84:929-935.

Guo Y, Mannari V, Patel P, Massingill J. Selfemulsifiable soybean oil phosphate ester polyols for low-VOC corrosion resistant coatings. J Coat Technol Res. 2006; 3(4):327-331.

Guo A, Cho Y, Petrovic ZS. Structure and properties of halogenated and nonhalogenated soy-based polyols. J Polym Sci Pol Chem. 2000 Aug; 38:39003910.

Guo A, Demydov D, Zhang W, Petrovic ZS.
Polyols and polyurethanes from hydroformylation of soybean oil. J Polym Environ. 2002 Apr; 10(12):49-52.

Guo A, Javni I, Petrovic Z. Rigid polyurethane foams based on soybean oil. J Appl Polym Sci. 2000 Jul; 77(2):467-473.

Herrington R, Nafziger HK, Moore R, Casati F, Lidy W. Polyurethane flexible foams. Midland, MI: The DOW Chemical Company; 1997.

Hongyu Fan, Ali T., Rigid Polyurethane Foams Made from High Viscosity Soy-Polyols. JAPS. 2012.

Jackson M, King J. Lipase-catalyzed glycerolysis of soybean oil in supercritical carbon dioxide. J Am Oil Chem Soc. 1997; 74(2):103-106.

Javni, I. Pyo Hong, D. and.Petrovic, Z.S. Polyurethanes from Soybean Oil, Aromatic, and Cycloaliphatic Diamines by NonIsocyanate Route. J Appl Polym Sci. 2012.

Javni I, Zhang W, Petrovic ZS. Soybean oil-based polyisocyanurate rigid foams. J Polym Environ. 2004; 12:123-129.

Kiatsimkul P, Suppes GJ, Hsieh FH, Lozada ZR, Tu YC. Preparation of high hydroxyl equivalent weight polyols from soybean oil. Ind Crop Prod. 2008 Jan; 27(3): 257-264.

Kiatsimkul P, Suppes GJ, Sutterlin WR. Production of new soy-based polyols by enzyme hydrolysis of bodied soybean. Ind Crop Prod. 2007, 25(2):202209.

Kim K, Jeong JH, Kim IJ, Kim HS. Carbon coatings with olive oil, soybean oil and butter on nanoLiFePO4. J Power Sources. 2007; 167:524-528.

Krompiec S, Jerzy J, Majewski J, Grobelny J. Isomerization of vegetable oils catalyzed by ruthenium complexes. Pol J Appl Chem. 1998; 42:43-48.

Kiatsimkul P, Sutterlin WR, Suppes GJ. Selective hydrolysis of epoxidized soybean oil by commercially available lipases: Effects of epoxy group on the enzymatic hydrolysis. J Mol Catal B-Enzym. 2006 May; 41:55-60.

Knothe G, Derksen JTP, editors. Recent developments in the synthesis of fatty acid derivatives. Champaign, IL: American Oil Chemists' Society; 1999. 
Klaas M, Warwel S. Chemoenzymatic epoxidation of unsaturated fatty acid esters and plant oils. J Am Oil Chem Soc. 1996; 73(11):1453-1457.

Krishna SH, Karanth NG. Lipases and lipasecatalyzed esterification reactions in nonaqueous media. Catal Rev. 2002; 44(4):499-591.

Kuncova G, Triska J, Vrchotova N, Podrazky O. The influence of immobilization of Pseudomonas sp. 2 on optical detection of polychlorinated biphenyls. Mater Sci Eng C-Bio. S. 2002 Sep; 21(1-2):195201.

Knezevic Z, Milosavic N, Bezbradica D, Jakovljevic Z, Prodanovic R. Immobilization of lipase from Candida rugosa on Eupergit ${ }^{\circ} \mathrm{C}$ supports by covalent attachment. Biochem Eng J. 2006; 30:269-278.

Kandanarachchi P, Guo A, Demydov D, Petrovic Z. Kinetics of the hydroformylation of soybean oil by ligand-modified homogeneous rhodium catalysis. J Am Oil Chem Soc. 2002; 79:1221-1225.

Lubguban AA, Tu YC, Lozada ZR, Hsieh FH, Suppes GJ. Functionalization via glycerol transesterification of polymerized soybean oil. J Appl Polym Sci. 2008 Dec; 112(19): 19-27.

Lu J, Khot S, Wool RP. New sheet molding compound resins from soybean oil. I. Synthesis and characterization. Polymer. 2005; 46(1):71-80.

Luo X, Mohanty A, Misra M. Water-Blown Rigid Biofoams from Soy-Based Biopolyurethane and Microcrystalline Cellulose. J Am Oil Chem Soc. 2012; 89:2057-2065.

Lozada Z, Suppes GJ, Hsieh FH, Lubguban AA. Tu YC. Preparation of polymerized soybean oil and soy-based polyols. J Appl Polym Sci. 2009 May; 112(4):2127-2135.

Larock R, Dong X, Chung S, Reddy C, Ehlers L. Preparation of conjugated soybean oil and other natural oils and fatty acids by homogeneous transition metal catalysis. J Am Oil Chem Soc. 2001; 78:447-453.

Lo SK, Baharin BS, Tan CP, Lai OM. Lipasecatalysed production and chemical composition of diacylglycerols from soybean oil deodoriser distillate. Eur J Lipid Sci Technol. 2004; 106, 218-224.

Li Y, Luo X, Hu S. Bio-based Polyols and Polyurethanes. 2015. SpringerBriefs in Green Chemistry for Sustainability, DOI 10.1007/978-3319-21539-6-2, p.23-24.
Li, Y., Sun, X.C. (2015, July 25) Polyols from epoxidized soybean oil and alpha hydroxyl acids and their adhesion properties from UV polymerization. Int J Adhes Adhes. doi: http://dx.doi.org/10.1016/j. ijadhadh.2015.07.013.

Lin B, Yang L, Dai H, Yi A. Kinetic studies on oxirane cleavage of epoxidized soybean oil by methanol and characterization of polyols. J Am Oil Chem Soc. 2008; 85:113-117.

Liu, Zengshe, and Sevim Z. Erhan. "Ring-opening polymerization of epoxidized soybean oil." J Am Oil Chem Soc. 2010; 87(4):437-444.

Lubguban AA, Tu YC, Lozada ZR, Hsieh FH, Suppes JG. Noncatalytic polymerization of ethylene glycol and epoxy molecules for rigid polyurethane foam applications. J Appl Polym Sci. 2009 Feb; 112:2185-2194.

Mielewski DF, Flanigan CM, Perry C, Zaluzec MJ, Killgoar PC. Soybean oil auto applications. Ind Biotech. 2005; 1:32-34.

McNeill G, Shimizu S, Yamane T. High-yield enzymatic glycerolysis of fats and oils J Am Oil Chem Soc. 1991 Jan; 68(1):1-5.

Mannari V, Massingill J. Two-component high-solid polyurethane coating systems based on soy polyols. J Coat Technol Res. 2006 Apr; 3(2):151-157.

Mello, V.M., Martins, G.B.C., Montenegro, M.A., Suarez, P.A.Z. Thermal processing of soybean oil to obtain bio-based polymers and bio-oil. Ind Crops Prod. 2014 Oct; 66(2015):255-261.

Nayak PL. Natural oil based polymers: Opportunities and challenges. Rev Macromol Chem Phys. 2000; C40(1): 1-21.

Noureddini H, Harmeier S. Enzymatic glycerolysis of soybean oil. J Am Oil Chem Soc. 1998; 75(10):1359-1365.

Noureddini H, Harkey DW, Gutsman MR. A continuous process for the glycerolysis of soybean oil. J Am Oil Chem Soc. 2004 Feb; 81:203-207.

Petrovic ZS. Polyurethanes from vegetable oils. Polym Rev. 2008 Jan; 48(1):109-155.

Powers PO. Mechanism of the heat bodying linseed oil. J Polym Sci. 1950; 5(6): 741-743.

Park Y, Pastore G, de Almeida M. Hydrolysis of soybean oil by a combined lipase system. J Am Oil 
Chem Soc. 1988 Feb; 65(2):252-254.

Petrovic ZS, Zlatanic A, Lava CC, SinadinovicFiser S. Epoxidation of soybean oil in toluene with peroxoacetic and peroxoformic acids-kinetics and side reactions. Eur J Lipid Sci Technol. 2002; 104:293-299.

Pechar TW, Sohn S, Wilkes GL, Ghosh S, Frazier $\mathrm{CE}$, Fornof AR, Long TE. Characterization and comparison of polyurethane networks prepared using soybean-based polyols with varying hydroxyl content and their blends with petroleum-based polyols. J Appl Polym Sci. 2006 Aug; 101(3):14321443.

Petrovic ZS, Guo A, Javni I, Cvetkovi I, Hong DP. Polyurethane networks from polyols obtained by hydroformylation of soybean oil. Polym Int. 2008; 57(2):275-281.

Petrovic S.Z, Mihail I. Polymerization of Soybean Oil with Superacids, Soybean-Applications and Technology, ISBN: 978-953-307-207-4, InTech.

Refvik M, Larock R, Tian Q. Ruthenium-catalyzed metathesis of vegetable oils. J Am Oil Chem Soc. 1999; 76:93-98.

Rosu R, Uozaki Y, Iwasaki Y, Yamane T. Repeated use of immobilized lipase for monoacylglycerol production by solid-phase glycerolysis of olive oil. J Am Oil Chem Soc. 1997; 74(4):445-450.

Schmidt HT, Kroczynski M, Maddox J, Chen Y, Josephs R, Ostafin AE. Antibody-conjugated soybean oil-filled calcium phosphate nanoshells for targeted delivery of hydrophobic molecules. J Microencapsul. 2006 Nov; 23(7):769-781.

Shen L, Zhao Y, Hsieh F, Tekeei A, Suppes GJ. Density Modeling of Polyurethane Box Foam. Polym Eng Sci. 2013.

Sinadinović-Fišer S, Janković $M$, Petrović Z Kinetics of in situ epoxidation of soybean oil in bulk catalyzed by ion exchange resin. J Am Oil Chem Soc. 2001; 78:725-731.

Suppes GJ, Hsieh F, Tekeei A, Ghoreishi R, Zhao Y, Shen L. Simulation of Urethane Reaction for Both Analytical Methods and Formulation Development. Polyurethane Technical Conference; 2013 Sep. Phoenix, Arizona, USA.

Szycher M. Szycher's Handbook of Polyurethanes. Boca Raton, FL: CRC Press LLC; 1999.
Tan, S. Polyurethane Rigid Foam from Soybean Oilbased Polyol (2010). MS Thesis, pp. 14-15.

Teng G, Gao L, Xiao G, Liu H. Transesterification of soybean oil to biodiesel over heterogeneous solid base catalyst. Energ Fuel. 2009; 23(9):4630-4634.

Tu YC, Kiatsimkul P, Suppes GJ, Hsieh FH. Physical properties of water-blown rigid polyurethane foams from vegetable oil-based polyols. J Appl Polym Sci. 2007 Jul; 105(2):453-459.

Tian Q, Larock RJ. Model studies and the ADMET polymerization of soybean oil. J Am Oil Chem Soc. 2002; 79:479-488.

Tran P, Graiver D, Narayan R. Ozone-mediated polyol synthesis from soybean oil. J Am Oil Chem Soc. 2005; 82:653-659.

Tu YC, Suppes GJ, Hsieh FH. Water-blown rigid and flexible polyurethane foams containing epoxidized soybean oil triglycerides. J Appl Polym Sci. 2008 Jul; 109(1):537-544.

Vlcek T, Petrovic Z. Optimization of the chemoenzymatic epoxidation of soybean oil. J Am Oil Chem Soc. 2006; 83(3):247-252.

Wool RP, Sun XS. Bio-based polymers and composites. Burlington, MA: Elsevier Academic Press; 2005.

Yoshida H, Alexander J. Enzymatic hydrolysis of fractionated products from thermally oxidized in the laboratory. Lipids. 1983; 18(6):402-407.

Yesiloglu Y. Utilization of bentonite as a support material for immobilization of Candida rugosa lipase. Process Biochem. 2005; 40:2155-2159.

Zhao, Y., Fu, Z., Tekeei, A., Suppes, G. J. Modeling Impact of Catalyst Loading on Polyurethane Foam Polymerization. Appl Catal. 2013.

Zhong B, Shaw C, Rahim M, Massingill J. Novel coatings from soybean oil phosphate ester polyols. J Coat Technol. 2001; 73(915):53-57. 